\title{
Summer reading: science in fiction
}

\author{
Though somewhat rare, there are a few good fiction books to be found with refreshingly \\ realistic biologists as central characters in laboratory settings.
}

This summer, whether traveling to a vacation destination or just taking a break to enjoy the sunshine, why not leave the research papers behind and instead bring along a good novel? Perhaps a story of a scientist, with some ethical dilemmas, romance or riveting plot twists thrown in for good measure, might be just the book you seek to sprawl out with on a hot summer day?

Realistic scientist characters, especially biologists, at work at the bench are relatively rare in literature; scientists in fiction are usually reduced to one of several stereotypes. The classic 'mad scientist' or 'evil genius' is single-minded and willing to cross the lines of acceptable moral behavior in the name of the scientific quest. In thrillers that border on science fiction, the adventurer/scientist usually has an amazing span of knowledge from particle physics to genetic engineering to plate tectonics, which he or she uses in a heroic fashion to solve life-or-death problems. Or you might find an eccentric white-coated lab 'egghead', toiling alone at the bench, with no real social skills or interests outside the lab.

How many times have you shaken your head at these caricatures? With a little digging, however, compelling, sympathetic and believable portrayals of biologists in laboratory settings can be found. Though not a comprehensive list, described here are a few novels with refreshingly realistic biologists as central characters. These characters are serious researchers, and much of the stories revolve around their struggles and triumphs in their lab work, but their work is tightly intertwined with their families, friendships and love lives—and sometimes in page-turning plot twists.

The biology lab is a particularly ripe setting for spinning captivating tales of unethical scientific behavior, as highlighted in two selections. In Cantor's Dilemma (Penguin), the best-known fiction work by chemist Carl Djerassi, Isidore Cantor is a prominent scientist with a Nobel Prize-worthy hypothesis about cancer biology. Cantor assigns his top postdoc to obtain experimental proof, but after publishing the brilliant result, questions arise about its reproducibility, and Cantor is tipped off anonymously that his postdoc has perhaps manipulated the data. Does he confront his postdoc and come clean? Conversely, in Intuition (Dial Press), by Allegra Goodman, the story centers around the fallout experienced in a successful cancer lab after
Robin, a struggling postdoc, accuses a fellow postdoc and ex-boyfriend, Cliff, of falsifying data that seems too good to be true.

Another rich theme facilitated by a research setting is the internal conflicts that scientists face with their work, especially when it comes to the potential for wealth and prestige. Long for this World (Mariner Books) by Michael Byers is the story of Henry Moss, a doctor who has to decide whether the possibility of saving the life of a favorite young patient afflicted with a disease that causes rapid aging is worth the personal risks of applying an untested therapy he has discovered. Moss also questions whether to go public with his 'fountain of youth' therapy to prevent human aging, for certain financial gain. In the 1925 classic, Arrowsmith (Signet Classics), by Sinclair Lewis, Martin Arrowsmith struggles to find satisfaction in his work, feeling the pull between wanting to return to performing pure, independent research versus the prestige of hospital and applied medical research positions.

The potential impacts of biology research on humanity also make for compelling fictional stories. In Experimental Heart (Cold Spring Harbor Laboratory Press) by Jennifer Rohn (who is also a cell biology researcher), the main character, Andy, helps his love interest, Gina, in a race to perform illegal experiments to test a vaccine on mice to ensure that it is not dangerous, before a collaborator with dubious morals begins clinical trials in Africa without any previous animal testing. In Mendel's Dwarf (Penguin) by Simon Mawer (himself a former biology teacher), Benedict Lambert, a geneticist with dwarfism, pursues the discovery of the gene responsible for his condition, and then must deal with the societal impacts of his findings on being able to select genetic traits in human offspring and, more personally, even in his own child.

These books are not just entertaining tales of biologists at work; they also make the reader think about the unique issues and potential for moral challenges that come with performing life science research. Other titles under the broader umbrella of 'science in fiction' can be found at LabLit (http://www.lablit.com/), an online magazine created by Jennifer Rohn, which aims to raise the profile of this genre and of which you can read more about on Methagora. Keep on reading! 